\title{
Kelimpahan dan Keanekaragaman Kupu-Kupu Nymphalidae di Hutan Kota Kuwil Minahasa Utara Sulawesi Utara
}

\author{
Adelia S. Modeong ${ }^{a^{*}}$,Roni Koneria, Farha N.J.Dapasa \\ aJurusan/Prodi.Biologi, Fakultas MIPA, Universitas Sam Ratulangi
}

K A T A K U C I

Parthenos shylva salentia Idea blanchardii

Hutan Kota Kuwil

Minahasa Utara

\begin{abstract}
A B S T R A K
Nymphalidae merupakan famili yang memiliki jumlah spesies terbesar dibandingkan dengan famili lainnya. Kupu-kupu tersebut dalam suatu ekosistem memiliki peran yang penting yaitu sebagai polinator dalam penyerbukan, dan dapat dijadikan bioindikator lingkungan. Data kelimpahan dan keanekaragaman kupukupu Nymphalidae pada kawasan hutan Kuwil pada saat ini belum tersedia. Penelitian ini bertujuan untuk menganalisis kelimpahan dan keanekaragaman spesies kupu-kupu famili Nymphalidae di Hutan Kota Kuwil Minahasa Utara. Teknik pengambilan sampel menggunakan metode transek. Penempatan transek pada setiap habitat dilakukan secara Purposive Random Sampling. Tipe habitat pada lokasi penelitian adalah pinggir sungai, hutan dan kebun. Pengambilan sampel dilakukan sepanjang garis transek menggunakan sweepnet. Komposisi spesies Nymphaldae ditemukan sebanyak 21 spesies dan 208 individu. Spesies yang memiliki kelimpahan tertinggi adalah Parthenos shylvia dan Idea blnchardii. Analisis keanekaragaman didapatkan kelimpahan spesies Nymphalidae pada habitat pinggir sungai sebesar 101 individu, hutan 70 individu, dan kebun 37 individu. Indeks keanekargaman spesies di pinggir sungai 2,55, hutan 2,41 dan kebun 2,03. Indeks kekayaan spesies pinggir sungai 3,25, hutan 3,06 dan kebun 2,49 . Indek kemerataan spesies pinggir sungai memiliki nilai yang sama dengan hutan yaitu sebesar 0,91, sedangkan pada kebun sebesar 0,88. Berdasarkan nilai tersebut didapatkan bahwa kelimpahan, indeks kekayaan dan indeks keanekaragaman spesies kupu-kupu Nymhalidae tertinggi ditemukan pada habitat pinggir sungai.

A B S T R A C T

Nymphalidae is a family with the largest number of species compared to other families. This butterfly has an important role as a pollinator for pollination in an ecosystem, and can be used as an environmental bioindicator. Data on abundance and variation of Nymphalidae butterflies in the Kuwil forest area was not avilable. This study aims to analyze the abundance and species of Nymphalidae family butterflies in the Forest of the Northern Minahasa Region. The sampling technique that was used is the transect method. Transect placement in each habitat was done by Purposive Random Sampling. The habitat types at the study site are on the river banks, forests and gardens. Sampling was carried out along the transect line using sweepnet. The composition of the Nymphaldae species found was 21 species and 208 individuals. The species with have the highest abundance are Parthenos shylvia and Idea blnchardii. Diversity
\end{abstract}

K E Y W O R D S

Parthenos shylva slentia

Idea blanchardii

Kuwil urban Forest

North Minahasa
TERSEDIA ONLINE

01 Agustus 2020

\section{Pendahuluan}

Hutan Kota Kuwil merupakan salah satu hutan kota yang terletak di Desa Kuwil Kecamatan Kalawat, Airmadidi, Minahasa Utara, Sulawesi Utara. Hutan Kuwil yang dijadikan sebagai hutan kota telah ditetapkan melalui Peraturan Daerah (Perda) Kabupaten Minahasa Utara Nomor 2 tahun 2012 dengan luas kawasan $\pm 43 \mathrm{Ha}$. Hutan kota ini berfungsi untuk memperbaiki dan menjaga iklim mikro dan nilai estetika, meresapkan air, menciptakan keseimbangan dan keserasian lingkungan fisik kota dan mendukung pelestarian keanekaragaman hayati (Azahra et al, 2016). Hutan kota ini juga berpotensi sebagai sarana pelestarian

*Corresponding author:

Email address: adeliamodeong24@gmail.com

Published by FMIPA UNSRAT (2020) 
keanekaragaman hayati termasuk di antaranya kupu-kupu Nymphalidae. Kawasan Hutan Kota Kuwil memiliki berbagai tipe ekosistem seperti ekosistem sungai, ekosistem hutan dan di luar kawasan terdapat ekosistem kebun yang dikelolah oleh masyarakat.

Pada saat ini dengan bertambahnya jumlah penduduk di sekitar kawasan hutan tersebut, Hutan Kuwil mengalami ancaman, yang disebabkan oleh aktivitas masyarakat. Aktivitas masyarakat akan berdampak terhadap keanekaragaman kupu-kupu Nymphalidae di kawasan tersebut. Beberapa penelitian kupu-kupu telah dilakukan pada beberapa hutan kota di Indonesia seperti penelitian kupu-kupu (Rhopalocera) di Kawasan Hutan Kota BNI Banda Aceh menemukan sebanyak 6 spesies Nymphalidae (Alfida, 2016). Penelitian kelimpahan dan keanekaragaman spesies kupu-kupu (Lepidoptera; Rhopalocera) pada berbagai tipe habitat di Hutan Kota Muhammad Sabki Kota Jambi ditemukan sebanyak 23 spesies Nymphalidae (Estalita, 2016). Penelitian kupu-kupu pada beberapa Hutan Kota di Jakarta Timur diperoleh 8 spesies Nymphalidae (Azahra et al, 2016). Penelitian kupu-kupu Nymphalidae yang pernah dilakukan di Sulawesi Utara pada hutan kota kota di Minahasa Utara yaitu pada Hutan Kota Kaki Dian ditemukan 18 spesies Hutan Kota Kenangan 12 spesies dan di Hutan Kota Talise didapatkan 9 spesies Nymphalidae (Koneri et al., 2020).

Data kelimpahan dan keanekaragaman Nymphalidae di kawasan Hutan Kota Kuwil belum pernah diteliti dan dipublikasikan. Berdasarkan permasalahan tersebut maka perlu dilakukan penelitian tentang kelimpahan dan keanekaragaman kupu-kupu Nymphalidae. Hal ini disebabkan karena famili Nymphalidae memiliki jumlah spesies terbesar dibandingkan dengan famili kupu-kupu lainnya. Penelitian ini sangat penting dilakukan karena Hutan Kota Kuwil merupakan salah satu kawasan konservasi dan tujuan wisata, maka kelimpahan dan keanekaragaman fauna khususnya kupu-kupu Nymphalidae perlu didata. Penelitian ini bertujuan untuk menganalisis kelimpahan dan keanekaragaman spesies kupu-kupu famili Nymphalidae di Hutan Kota Kuwil Minahasa Utara, Sulawesi Utara.

\section{Material dan Metode}

Penelitian dilaksanakan pada bulan September sampai dengan November 2019. Lokasi penelitian bertempat di Hutan Kota Kuwil, Desa Kuwil, Kecamatan Kalawat, Kabupaten Minahasa Utara, Sulawesi Utara. Habitat yang dijadikan sebagai tempat pengambilan sampel adalah habitat pinggir sungai, habitat hutan dan habitat kebun.

Teknik pengambilan sampel menggunakan metode transek. Pada setiap tipe habitat dibuat tiga garis transek dengan panjang $200 \mathrm{~m}$. Pengambilan sampel dimulai dari jam 08:00-14:00 WITA. Penempatan transek pada setiap habitat dilakukan secara Purposive Random Sampling. Sampel kupu- kupu yang diambil dalam penelitian ini adalah kupukupu dewasa (Pollard dan Yates 1993).

Pengambilan sampel dilakukan sepanjang garis transek dengan menggunakan jaring serangga. Kupu-kupu yang dikoleksi hanya satu spesimen setiap spesies, bila ditemukan tiap spesies yang sama jenis, maka kupu-kupu tersebut akan dilepaskan kembali (Sari et al, 2019).

Kupu-kupu yang menjadi sampel disimpan dalam amplop-amlop kertas papilot berbentuk segitiga yang berukuran $30 \mathrm{~cm}$ x $20 \mathrm{~cm}$. Proses identifikasi dan klasifikasi spesimen kupu-kupu menggunakan buku identifikasi Peggie (2011; 2014; 2016), dan Van-Wright dan de Jong (2003).

Analisis data yang akan dilakukan dalam penelitian ini meliputi: Indeks kekayaan spesies (S), Indeks keanekaragaman spesies ( $\left.\mathrm{H}^{\prime}\right)$, dan Indeks kemerataan spesies (E) (Magurran 1988), dengan rumus sebagai berikut:

Indeks keanekaragaman $\left(\mathrm{H}^{\prime}\right)$

Keterangan :

$$
\mathrm{H}^{\prime}=-\sum_{i=1}^{S}(P i \ln P i)
$$

$\mathrm{Pi}: \mathrm{n} / \mathrm{N}$

$\mathrm{H}^{\prime}$ : Indeks keanekargaman Shannon-Wiener

ni : Jumlah individu setiap spesies

$\mathrm{N}$ : Jumlah individu seluruh

Indeks kekayaan spesies (S)

$$
\mathrm{R}=\frac{S-1}{\ln \cdot N}
$$

Keterangan :

R: Indeks Richness

S: Jumlah spesies

$\mathrm{N}$ : Total individu dalam pengambilan sampel. Indeks Kemeratan $€$

$$
\mathrm{E}=\mathrm{H}^{\prime} / \mathrm{InS}
$$

Keterangan:
E: Indeks kemerataan (Evenness)
$\mathrm{H}^{\prime}$ : indeks kemerataan Shannon- Wiener
S: Jumlah spesies (n1, n2, n3.....)

\section{Hasil dan Pembahasan}

Hasil penelitian ditemukan sebanyak 21 spesies Nymphalidae dengan jumlah individu sebanyak 208 Individu. Spesies paling banyak didapatkan adalah Parthenos shylvia sebanyak 42 individu (20,19\%). Spesies Parthenos shylvia yang ditemukan memiliki ciri-ciri bagian dorsal dan ventral dominan berwarna orange, mempunyai corak hitam dan corak putih pada bagian pangkal dan ujung sayap. Spesies tersebut dominan didapatkan pada semua habitat. Spesies berikutnya yang banyak ditemukan adalah Idea blanchardii (22 individu atau 10.58\%). Idea blanchardii memiliki ciri-ciri bagian ventral dan dorsal dominan berwarna putih gading dan mempunyai corak hitam bergaris. Spesies yang paling sedikit ditemukan adalah Neptis ida dengan jumlah 2 individu (0,96\%) (Tabel 1). Neptis ida dengan ciri-ciri bagian dorsal berwarna dominan cokelat kehitaman mempunyai corak putih dan warna hitam pada bagian ujung sayap. 
Jumlah spesies Nymphalidae yang ditemukan di Hutan Kota Kuwil baru mencapai 10,99\% (21 spesies ditemukan/191 spesies yang ada di sulawesi $\mathrm{x}$ 100\%) dari seluruh spesies Nymphalidae yang terdapat di Pulau Sulawesi. Vane-Wright \& de Jong (2003) melaporkan bahwa jumlah spesies famili Nymphalidae yang ditemukan di Pulau Sulawesi sebanyak 191 spesies. Hasil penelitian menunujukkan bahwa jumlah spesies kupu-kupu anggota Nymphalidae ini jauh lebih banyak yang didapatkan dibandingkan dengan hutan kota lainnya yang terdapat di Minahasa Utara. Hasil penelitian kupu-kupu pada beberapa hutan kota di Minahasa Utara didapatkan spesies Nymphalidae pada Hutan Kota Kaki Dian 18 spesies, Hutan Kota Kenangan 12 spesies dan di Hutan Kota Talise hanya 9 spesies Nymphalidae (Koneri et al., 2020). Perbedaan jumlah spesies yang ditemukan sangat tergantung kepada beberapa faktor seperti kompleksitas struktur vegetasi penyusun hutan kota, lama pengambilan sampel, luas kawasan hutan kota dan waktu pengambilan sampel.

Spesies Parthenos shylvia merupakan spesies dengan individu terbanyak yang terdapat di ketiga habitat (hutan, kebun dan pinggir sungai). Hal ini dikarenakan spesies tersebut memiliki larva yang bersifat polifag (mempunyai jenis makanan lebih dari satu). Sifat polifag menyebabkan spesies tersebut dapat hidup dan berkembang pada berbagai habitat. Effendi (2009) melaporkan_bahwa tempat hidup dan makanan larva kupu-kupu bergantung dari berbagai jenis spesies tumbuhan dari berbagai famili. Spesies dengan jumlah individu yang paling sedikit yakni Neptis Ida. Hal tersebut disebabkan, karena kurangnya tanaman inang seperti dari famili tumbuhan Euphorbiaceae yang menjadi sumber makanan dari kupu-kupu di ketiga habitat tersebut (Lestari et al. 2018). Keberhasilan kolonisasi kupukupu tergantung pada habitat yang sesuai, dalam hal ini ketersediaannya sumber makanan.

Berdasarkan tipe habitat didapatkan bahwa kelimpahan spesies kupu-kupu tertinggi ditemukan di pinggir sungai (101 individu) dan diikuti dengan habitat hutan (70 individu). Kelimpahan terendah ditemukan pada habitat kebun dengan jumlah 37 individu (Gambar 1a). Perbedaan kelimpahan spesies sangat dipengaruhi oleh struktur dan kompleksitas dari vegetasi penyusun habitat sebagai sumber pakan dari kupu-kupu tersebut. Effendi (2009) menyatakan bahwa kelimpahan kupu-kupu pada suatu habitat dipengaruhi oleh penyebaran dan banyaknya tumbuhan pakan, baik sebagai inang bagi larva maupun sebagai sumber nektar bagi imago.

Indeks keanekaragaman spesies (H') kupu-kupu famili Nymphalidae tertinggi juga ditemukan di habitat pinggir sungai $(2,52)$. Indek keanekaragaman spesies kupu-kupu tertinggi berikutnya diikuti oleh habitat hutan $(2,41)$, sedangkan yang terendah terdapat pada habitat kebun $(2,03)$ (Gambar 1b). Indeks Keanekaragaman spesies yang ditemukan di hutan kota kuwil tergolong kategori sedang, karena nilai indeks keanekaragaman spesiesnya berkisar antara 2,03-2,51. Indeks keanekaragaman spesies ( $\left.H^{\prime}\right)$ memiliki nilai kecil dari 1,5 tergolong rendah, jika nilai $\mathrm{H}^{\prime}$ antara 1,5 sampai 3,5 tergolong sedang dan jikan nilai $\mathrm{H}^{\prime}>3,5$ dikategorikan keanekaragaman tinggi (Magurran 1988). Lestari et al. (2018) menyatakan bahwa keanekaragaman kategori sedang menandakan bahawa suatu komunitas memiliki kompleksitas yang sedang pada struktur habitat dan keragaman bentuk vegetasi. Pada komunitas sedang tidak banyak terjadi interaksi antar spesies dibandingkan dengan komunitas yang sudah mencapai klimaks.

Indeks kekayaan spesies (R) kupu-kupu tertinggi ditemukan pada habitat pinggir sungai yaitu sebesar 3,25 lalu diikuti oleh habitat hutan $(3,06)$. Indeks kekayaan spesies terendah terdapat pada habitat kebun (2,49)(Gambar 1b). Indek kekayaan spesies pada habitat pinggir sungai tergolong sedang, sedangkan pada habitat kebun termasuk kategori rendah. Menurut Misra (1968) Indeks Kekayaan Spesies $(R)<2,5$ menunjukkan tingkat indeks kekayaan jenis yang rendah, sedangkan $R>2,5$ sampai $\mathrm{R}<4$ menunjukkan tingkat kekayaan jenis yang sedang dan jika $\mathrm{R}>4$ menunjukkan tingkat kekayaan jenis yang tinggi. Menurut Wahyuni et al. (2014) indek kekayaan spesies merupakan perbandingan jumlah spesies yang ditemukan di suatu lokasi dengan jumlah dari masing-masing spesies yang ditemukan.

Indeks kemerataan spesies (E) kupu-kupu tertinggi ditemukan pada habitat hutan dan pinggir sungai $(0,91)$, sedangkan indeks kemerataan spesies terendah ditemukan di habitat kebun $(0,88)$ (Gambar 1d). Indeks kemerataan spesies spesies kupu-kupu pada hutan kota kuwil dikategorikan tinggi. Indeks kemerataan spesies (E) dengan nilai ' $0<0,3$ tergolong rendah, nilai antara 0,3-0,6 tergolong kemerataan sedang dan nilai indeks kemerataan $\left(E^{\prime}\right)>0,6$ dikategorikan kemerataan tinggi (Magurran 1988). Fachrul (2012) menyatakan bahwa indek kemerataan spesies yang tinggi menunjukkan bahwa jumlah individu masing-masing spesies pada lokasi penelitian tersebut relatif sama, tidak ada spesies yang sangat dominan. Kemerataan spesies dikatan rendah jika nilai niai $\mathrm{E} \approx 0$. Kemerataan spesies menunjukkan komposisi jumlah individu per spesies pada suatu habitat tertentu. Indek kemerataan semakin tinggi menunjukkan bahwa persebaran spesies pada habitat tersebut merata. Hal ini menunjukkan bahwa semakin baik pula kondisi lingkungan tersebut sehingga mampu mendukung kelangsungan hidup spesies tersebut

Kelimpahan spesies, indek kekayaaan dan indek keanekaragaman spesies kupu-kupu Nymphalidae tertinggi ditemukan pada habitat sungai dibandingkan dengan habitat lainnya. Hal ini disebabkan habitat pinggir sungai memiliki tanaman berbunga yang beragam seperti famili Asteraceae (Euphatorium), Rubiaceae (Mussaenda) Moraceae (Ficus), Euphorbiaceae (Euphorbia), dan Acanthaceae (Hemigraphis) sebagai kebutuhan 
pakan untuk kupu-kupu. Menurut Thomas et al. (2004) keberadaan kupu-kupu dalam suatu habitat sangat tergantung pada ketersediaan tumbuhan pakan. Achmad (2002) berpendapat bahwa distribusi dan kelimpahan sumber pakan larva merupakan salah satu faktor yang memberikan pengaruh besar terhadap kelangsungan hidup larva kupu-kupu, dikarenakan makanan utamanya adalah nektar bunga. Semakin banyak nektar yang tersedia, maka semakin banyak pula imago yang datang mengunjungi tempat tersebut. Menurut Effendi (2009) bahwa kelimpahan kupu-kupu berkorelasi dengan kelimpahan tumbuhan penghasil nektar yang menyediakan energi dan nutrisi bagi kupu-kupu, dan keragaman kupu-kupu tidak hanya dipengaruhi oleh keberadaan volume nektar, tetapi dipengaruhi juga oleh kekayaan tumbuhan nektar dan kandungan gulanya (Koneri et al. 2020)

Habitat pinggir sungai merupakan lokasi yang sedikit terbuka, sehingga lebih dominan terpapar cahaya langsung. Cahaya akan dapat menarik kupukupu, karena kupu-kupu membutuhkan cahaya untuk menjaga keseimbangan suhu tubuh dari kupukupu tersebut (Connor et al. 2003).

Habitat kebun merupakan lokasi yang terdapat sedikit individu kupu-kupu, hal ini dikarenakan habitat perkebunan sering mendapat gangguan dari manusia seperti pengolahan tanah, penyiangan vegetasi dan penggunaan herbisida. Hal ini akan menyebabkan berkurangnya tanaman inang dari kupu-kupu Indeks kemerataan antara pinggir sungai dan kebun memiliki indeks keanekaragaman yang sama (Effendi, 2009).

Tabel 1. Spesies kupu-kupu famili Nymphalidae pada tiga habitat di Hutan Kota Kuwil

\begin{tabular}{|c|c|c|c|c|c|c|}
\hline \multirow{2}{*}{ No } & \multirow{2}{*}{ Spesies } & \multicolumn{3}{|c|}{ Habitat } & \multirow{2}{*}{ Jumlah } & \multirow{2}{*}{$\%$} \\
\hline & & Hutan & Kebun & $\begin{array}{l}\text { Pinggir } \\
\text { Sungai }\end{array}$ & & \\
\hline 1 & $\begin{array}{l}\text { Parthenos } \\
\text { shylvia }\end{array}$ & 12 & 13 & 17 & 42 & 20,19 \\
\hline 2 & Idea blanchardii & 9 & 5 & 8 & 22 & 10,58 \\
\hline 3 & $\begin{array}{l}\text { Lasippa } \\
\text { neriphus }\end{array}$ & 11 & 0 & 6 & 17 & 8,17 \\
\hline 4 & Ypthima loryma & 0 & 2 & 15 & 17 & 8,17 \\
\hline 5 & Junonia hedonia & 4 & 4 & 7 & 15 & 7,21 \\
\hline 6 & $\begin{array}{l}\text { Danaus ismare } \\
\text { alba }\end{array}$ & 1 & 0 & 11 & 12 & 5,77 \\
\hline 7 & Idiopsis juventa & 1 & 0 & $\begin{array}{c}1+ \\
9\end{array}$ & 10 & 4,81 \\
\hline 8 & Idiopsis vitrea & 4 & 0 & 5 & 9 & 4,33 \\
\hline 9 & Parantica cleona & 7 & 2 & 0 & 9 & 4,33 \\
\hline 10 & Pareronia tritaea & 0 & 2 & 7 & 9 & 4,33 \\
\hline 11 & Mycalesis & & & & & \\
\hline & janarda & 5 & 0 & 2 & 7 & 3,37 \\
\hline 12 & Ypthima nynias & 4 & 0 & 3 & 7 & 3,37 \\
\hline 13 & Euploea & & & & & \\
\hline & leucostictos & 0 & 3 & 2 & 5 & 2,40 \\
\hline 14 & Mycalesis nicotia & 5 & 0 & 0 & 5 & 2,40 \\
\hline 15 & Cyrestis strigata & 0 & 2 & 2 & 4 & 1,92 \\
\hline 16 & Euthalia & & & & & \\
\hline & aconthea & 0 & 0 & 4 & 4 & 1,92 \\
\hline 17 & Cyrestis paulinus & 3 & 0 & 0 & 3 & 1,44 \\
\hline 18 & Doleschallia & & & & & \\
\hline & polybete & 1 & 2 & 0 & 3 & 1,44 \\
\hline 19 & Euploea algea & 0 & 2 & 1 & 3 & 1,44 \\
\hline 20 & Mycalesis & & & & & \\
\hline & horsfieldi & 3 & 0 & 0 & 3 & 1,44 \\
\hline 21 & Neptis ida & 0 & 0 & 2 & 2 & 0,96 \\
\hline & Total & 70 & 37 & 101 & 208 & 100,00 \\
\hline
\end{tabular}

keanekaragaman kupu-kupu Nymphalidae di hutan Kuwil masih tergolong kategori sedang. Peningkatan keanekaragaman kupu-kupu dapat dilakukan dengan cara melakukan agroforestry di sekitar lahan perkebunan masyarakat yang berbatasan langsung dengan kawasan hutan kota Kuwil. Penanaman tumbuhan berbunga yang merupakan pakan kupukupu Nymphalidae seperti dari famili Asteraceae, Euphorbiacea, Moraceae, dan Acantahceae perlu dilakukan.

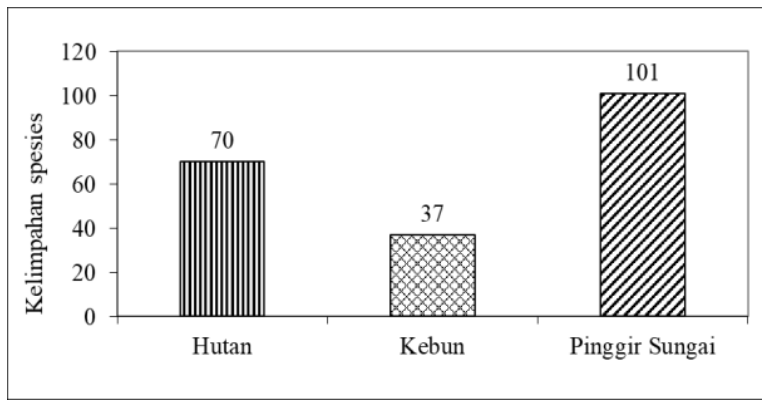

(a)

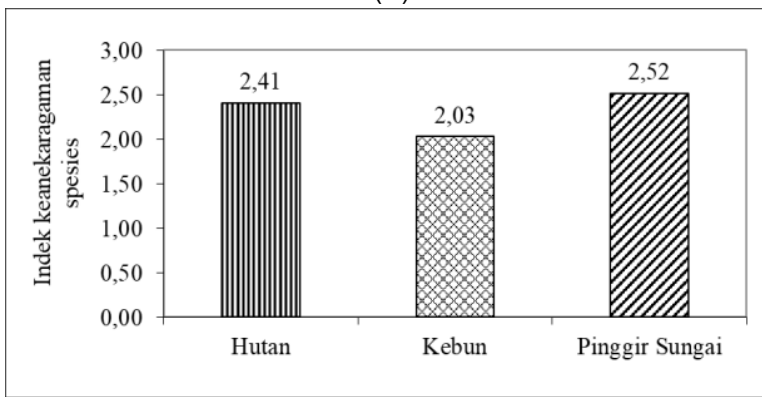

(b)

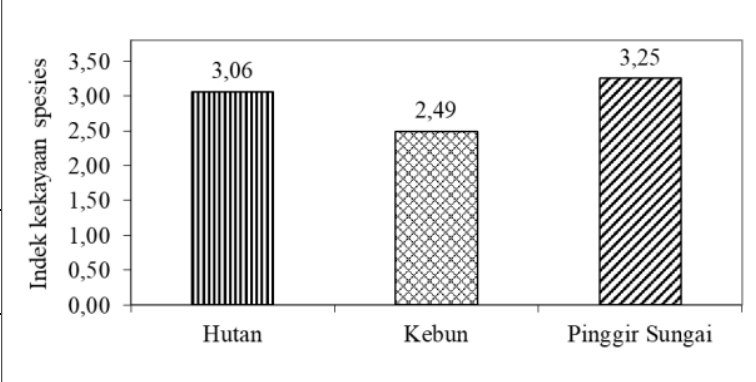

(c)

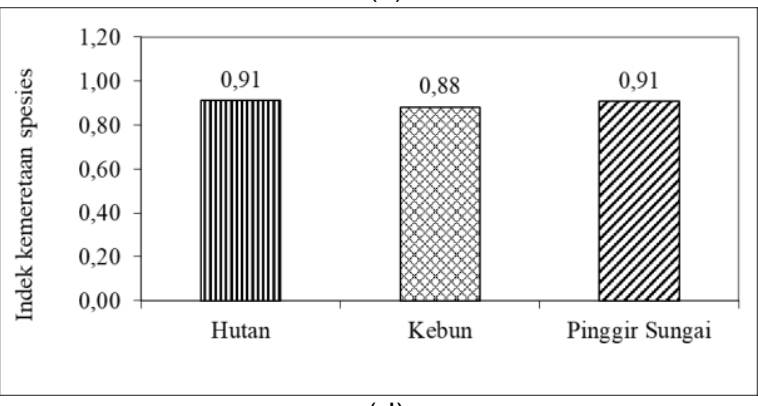

(d)

Gambar 1. Kelimpahan (a), Indeks keanekaragaman (b), Indeks kekayaan (c) dan indeks kemerataan Spesies kupu-kupu

Nymphalidae pada tiga tipe habitat di Hutan Kota Kuwil (d)

\section{Kesimpulan}

Jumlah spesies Nymphalidae yang ditemukan di Hutan Kota Kuwil Minahasa Utara sebanyak 21 spesies dan 208 individu kupu-kupu. Spesies yang 
paling banyak ditemukan adalah Parthenos shylva salentia. Kelimpahan spesies, indek keanekaragaman spesies dan indek kekayaan spesies tertinggi ditemukan pada habitat pinggir sungai kemudian hutan dan terendah pada habitat kebun.

\section{Daftar Pustaka}

Achmad A. Potensi dan Sebaran Kupu-kupu di Kawasan Taman Wisata Alam Bantimurung. Dalam: Workshop Pengelolaan Kupu-Kupu Berbasis Masyarakat. Bantimurung, 05 Juni 2002. On line at http://labkonbiodend.blogspot. com/2007/11/kupu-kupu2.html (accessed 09 Juni 2010). 2002.

Alfida, U. H. dan Eliyanti. 2016. Kupu-Kupu (Rhopalocera) di Kawasan Hutan Kota BNI Banda Aceh. Jurnal Biotik. 4(2): 117-127.

Azahra, S.D., Masyu'ud, B.N., dan Farikah, N. 2016. Perbandingan Komunitas Kupu-Kupu Pada Berbagai Tipe, Karakteristik dan Gangguan Lingkungan Hutan Kota. Media Konservasi. 21(2): 108-115.

Connor, E.F., Hafernik, J., Levy, J., Moore, V.L. and Rickman, J.K. 2003. Insect conservation in an urban biodiversity hotspot: The San Francisco Bay Area. Journal of Insect Conservation 6(4): 247-259

Effendi, M.A. 2009. Keragaman KupuKupu (Lepidoptera: Ditrysia) di Kawasan "Hutan Koridor" Taman Nasional Gunung Halimun-Salak Jawa Barat. Institut Pertanian Bogor. Bogor.

Fachrul, M.F. 2012. Metode Sampling Bioekologi. PT. Bumi Aksara. Jakarta.

Koneri, R., Maabuat, P. V., dan Nangoy, M. J. 2020. The Distribution and Diversity of Butterflies (Leptidoptera: Rhopalocera) In Various Urban Forest In North Minahasa Regency, North Sulawesi Province, Indonesia. Applied Ecology and Environmental Research 18(2): 2295-2314.

Koneri, R., Nangoy, M.J., dan Saroyo. 2020. Relationships Between Butterfly with Feed Plants in Sangihelslands, North Sulawesi, Indonesia. Pak. J. Biol. Sci., 23 (6): 804-812,

Lestari, V.C.,Erawan, T.S., Kasmara, M.H dan Wawan. 2018. Keanekaragaman Jenis Kupu-kupu Famili Nymphalidae dan Pieridae di Kawasan Cirengganis dan Padang Rumput Cikamal Cagar Alam Pananjung Pangandaran. Jurnal Agrikultura. 29(1): 1-8.

Maguran, A.E. 1998. Ecological Diversity And Its Mesurements. Croom Helm Limited. London.

Misra, 1968. Ecology W ork Book. Oxford \& IB Publishing Co, New Delhi.

Pollard, E., dan Yates, T.J. 1993. Method on Measuring Biodiversity in Tropical Forest. Capman and all, London.

Wahyuni, I,R. K., Tohir, Y., Widyaningrum, U., Prabawatidan R, Lydisari. 2014. Keanekaragman Jenis Herpetofauna di Jalur Cikaweni Pusat Pendidikan Konservasi Alam Bodogo (Ppkab), Resort Bodogol, Taman
Nasional Gunung Gede Pangrango. Depertemen Konservasi Sumberdaya Hutan dan Ekowisata. Fakultas Kehutanan. Institut Pertanian Bogor. Bogor.

Sari, R.P., Mawrni, E.D., Nurlatifah, A., Ulinuha, R., Sari, E.K.A., Fitri, A.R., Rachman, R.A., Affandi, M., Rosmanida, Fauiziyah, S., Irawanto, R. 2019. Keanekaragaman kupu-kupu (Insecta: Lepidoptera) di Kebun Raya Purwodadi, Pasuruan, Jawa Timur, Indonesia. Pros Sem Nas Masy Biodiv Indon. Vol. 2 (5): 172-178

Thomas, J.A.,Telfer, M.G., Roy, D.B., et al. (2004) Comprative Isses of Birtish butterfies. Birds, and plants and the global extinction. Science 303:1879-1881.

Vane-Wright,R.I., dan de Jong, R. 2003. The Butterflies ofSulawesi: annotated checklist for a critical island fauna. Zoo. Verh. Leiden 343:3267 